\title{
A Review of Human Reliability Needs in the U.S. Nuclear Industry
}

\section{International Symposium on Resilient Cognitive Systems - 2015 Resilience Week (RSW)}

\section{Ronald Laurids Boring}

The INL is a

U.S. Department of Energy

National Laboratory

operated by

Battelle Energy Alliance

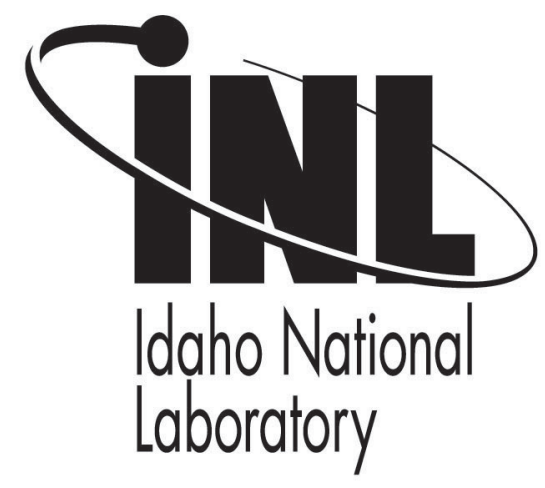

\section{August 2015}

This is a preprint of a paper intended for publication in a journal or proceedings. Since changes may be made before publication, this preprint should not be cited or reproduced without permission of the author. This document was prepared as an account of work sponsored by an agency of the United States Government. Neither the United States Government nor any agency thereof, or any of their employees, makes any warranty, expressed or implied, or assumes any legal liability or responsibility for any third party's use, or the results of such use, of any information, apparatus, product or process disclosed in this report, or represents that its use by such third party would not infringe privately owned rights. The views expressed in this paper are not necessarily those of the United States Government or the sponsoring agency. 


\title{
A Review of Human Reliability Needs in the U.S. Nuclear Industry
}

\author{
Ronald Laurids Boring \\ Human Factors, Controls, and Statistics Department \\ Idaho National Laboratory \\ Idaho Falls, Idaho 83415, USA \\ ronald.boring@inl.gov
}

\begin{abstract}
In this survey, 34 subject matter experts from the U.S. nuclear industry were interviewed to determine specific needs for human reliability analysis (HRA). Conclusions from the interviews are detailed in this article. A summary of the findings includes: (1) The need for improved guidance on the use of HRA methods generally and for specific applications. (2) The need for additional training in HRA to provide more hands-on experience in the application of HRA methods. (3) The development of HRA approaches suitable for advanced reactors, severe accident situations, and low-power and shutdown applications. (4) The refinement of HRA methods to account for factors such as crew variability, latent errors, more sophisticated dependency modeling, and errors of commission. (5) The continued need for simplified HRA methods appropriate for field applications. (6) The need for tighter coupling of HRA and human factors. (7) The need for improvements in the quantitative basis of HRA methods. These findings suggest the field of HRA is mature but still benefits from refinements.
\end{abstract}

Keywords-Human reliability analysis, user needs, survey

\section{INTRODUCTION}

The objective of this research is to understand ways in which human reliability analysis (HRA) is currently used and desired to be used in the future within the U.S. nuclear community. These findings serve as a foundation for future work to tailor existing HRA methods or develop new methods to meet regulatory and industry needs.

To better understand nuclear industry needs for HRA, subject matter experts (SMEs) in the U.S. nuclear industry with HRA experience were interviewed about their uses of and needs for HRA. Semi-structured interviews were conducted face-to-face, via email, or over the telephone. These informal interviews centered on answering the following main questions:

- What are the applications for HRA in the nuclear domain?

- What methods are used?

- Do the methods work for the applications? If not, what are the problems or issues?

- What are current HRA needs?

- What future applications require HRA?
These interviews helped identify potential areas for improvement in the Institute of Electrical and Electronics Engineers (IEEE) HRA standard, IEEE-1082, which is currently undergoing revision.

A total of 34 SMEs were interviewed. The SMEs were interviewed in 20 interview sessions, individually or in a group setting, over a two-month period. The SMEs consisted of HRA and probabilistic risk assessment (PRA) experts as follows: 19 SMEs involved in research, 9 SMEs involved in conducting HRAs and PRAs for current reactors, and 6 SMEs involved in HRAs and PRAs for new plant builds.

During the interviews, extensive notes were taken by the interviewer. These notes have been distilled down to key points that are found in Section II of this paper. Invariably, some interpretation by the author was necessary in transcribing key points. I have reviewed the summaries and believe they accurately reflect the intent of the comments made by the SMEs, even when a verbatim transcription was not possible. SME identities and responses have been kept fully anonymous in this paper.

\section{OVERALL SUMMARY OF FINDINGS}

\section{A. Introduction}

This section provides an overview of the findings across all interviews. No attempt has been made to prioritize the findings based on frequency of response. Instead, this summary represents an attempt to capture all relevant points identified by the HRA SMEs. The findings below may be translated into specific action items for improving the implementation of HRA.

\section{B. Current HRA Uses}

\section{1) HRA Methods in Use}

Table 1 below outlines which HRA methods are actively used or encountered by the SMEs. SME use of HRA methods is dominated by the Standardized Plant Analysis Risk-Human Reliability Analysis (SPAR-H) method [1] for simplified analysis. A Technique for Human Error Analysis (ATHEANA) [2-3] has been used for detailed analyses across all domains but is used infrequently in practice, primarily for 
unusual events not otherwise covered by other HRA methods. Legacy HRA methods like the Technique for Human Error Rate Prediction (THERP) [4] and The Accident Sequence Evaluation Program (ASEP) [5] methods are no longer widely encountered as standalone methods but are included as part of the Electric Power Research Institute (EPRI) HRA Calculator $^{\circledR}[6]$ used by licensees. The EPRI HRA Calculator ${ }^{\circledR}$ is now used by the majority of licensees. It features a toolkit approach of different methods, including THERP, ASEP, and SPAR-H from the U.S. Nuclear Regulatory Commission (NRC) and the Human Cognitive Response/Operator Reliability Experiments (HCR/ORE) and Cause Based Decision Tree (CBDT) methods from EPRI [7]. Support for HRA at the SMEs' institutions, based on current use patterns, should encompass those methods in the EPRI HRA Calculator $^{\circledR}$ as well as ATHEANA, which is proving the basis for many newer approaches like the fire HRA method in NUREG-1921 [8].

Table 1. HRA methods used by SMEs

\begin{tabular}{|c|c|c|c|}
\hline Method & $\begin{array}{c}\text { Current } \\
\text { Plants }\end{array}$ & $\begin{array}{c}\text { New } \\
\text { Plants }\end{array}$ & $\begin{array}{c}\text { Risk } \\
\text { Research }\end{array}$ \\
\hline THERP & $\checkmark^{*}$ & $\checkmark^{*}$ & $\checkmark^{*}$ \\
\hline ASEP & $\checkmark^{*}$ & & $\checkmark^{*}$ \\
\hline HCR/ORE & $\checkmark^{*}$ & & $\checkmark$ \\
\hline CBDT & $\checkmark^{*}$ & $\checkmark^{*}$ & $\checkmark^{*}$ \\
\hline SPAR-H & $\checkmark$ & $\checkmark$ & $\checkmark$ \\
\hline ATHEANA & & & $\checkmark$ \\
\hline
\end{tabular}

*Seen primarily through the EPRI HRA Calculator ${ }^{\mathbb{R}}$

\section{2) Current HRA Applications}

SMEs identified a number of applications for HRA in the interviews, as depicted in Table 2. These applications are detailed below in Sections II.B.2.a - II.B.2.g, along with a brief discussion of the users and the current needs for HRA. Additional HRA needs that aren't tied to specific applications are identified in Section III.

Table 2. HRA applications encountered by SMEs

\begin{tabular}{|c|c|c|c|c|}
\hline Application & $\begin{array}{c}\text { Paper } \\
\text { Section }\end{array}$ & $\begin{array}{c}\text { Current } \\
\text { Plants }\end{array}$ & $\begin{array}{c}\text { New } \\
\text { Plants }\end{array}$ & $\begin{array}{c}\text { Risk } \\
\text { Research }\end{array}$ \\
\hline Event Analysis & II.B.2.a & $\checkmark$ & & $\checkmark$ \\
\hline $\begin{array}{c}\text { Low Power and } \\
\text { Shutdown }\end{array}$ & II.B.2.b & $\checkmark$ & $\checkmark$ & $\checkmark$ \\
\hline Licensing & II.B.2.c & $\checkmark$ & $\checkmark$ & \\
\hline Human Factors & II.B.2.d & & $\checkmark$ & $\checkmark$ \\
\hline $\begin{array}{c}\text { Severe Accident } \\
\text { Mitigation }\end{array}$ & II.B.2.e & $\checkmark$ & $\checkmark$ & $\checkmark$ \\
\hline Fire & II.B.2.f & $\checkmark$ & & $\checkmark$ \\
\hline $\begin{array}{c}\text { Spent Fuel } \\
\text { Handling }\end{array}$ & II.B.2.g & $\checkmark$ & $\checkmark$ & \\
\hline
\end{tabular}

\section{a) Event analysis}

Following a reportable event at a plant, it is necessary to determine the risk significance of performance deficiencies through HRA. These may be performed to satisfy regulatory requirements such as to provide a counterpart to the U.S. Nuclear Regulatory Commission's Significance Determination Process (SDP) [9]. Deficiencies correspond to actual plant events. However, in some cases, events bring attention to potential vulnerabilities that have not actually resulted in unsafe plant events. In such cases, the purpose of the event analysis is to determine the risk significance of the potential vulnerability. The probabilistic risk assessment (PRA) and HRA are performed in response to the deficiency to determine the likelihood of such an event happening. As such, there is a strong emphasis in the event analysis on producing a quantitative result suitable for inclusion in an overall PRA. While the deficiency reflects an actual occurrence, the analysis focuses on the hypothetical occurrence of the deficiency, determining how likely such a deficiency would be to occur again or in the first place.

Because of the need for timely response to an identified deficiency, use of HRA for event analysis is centered on quick field applications. For this reason, the methods most commonly associated with event analysis are CBDT and SPAR-H, which serve as simplified HRA methods that allow quick quantification without the need for extensive on-site human factors expertise in its application.

In practice, analysts remarked that the quantitative estimates may be too conservative, especially for low power and shutdown applications. In terms of SPAR-H, there is also disagreement on the assignment level of the performance shaping factors (PSFs). Analysts may contend that particular PSFs do not properly represent conditions at the plant at the time of the deficiency. It requires considerable expertise to reconcile such disagreements.

HRA Needs: The primary HRA need for event analysis is to maintain simplified, quickly applied quantification methods and to continue to refine them in such a manner as to increase their fidelity for representing human performance during offnormal plant states.

\section{b) Low power and shutdown}

Low power and shutdown (LPSD) HRA is often closely related to event analysis, whereby the analysis often focuses on maintenance activities performed during plant outages rather than at-power control room activities. While in-controlroom actions can be important, LPSD activities are often characterized as being long-duration, ex-control-room, and less proceduralized. As such, the analyses need to include a greater consideration of the consequences of errors of commission, which can serve as triggering points for events at the plant. Because many advanced reactor designs feature a greater ability to perform maintenance activities at power, this topic is also of interest to analysts for new plants. However, the differences between current LPSD activities and advanced 
reactor activities need to be better understood and documented.

The first generation of HRA methods was developed primarily for control room activities at power. Newer methods like ATHEANA were directly borne out of the need also to address in- and ex-control room activities under different conditions such as LPSD, while methods like SPAR-H have included specific coverage of LPSD considerations like the increased time windows for task completion. Even with the development of HRA to address LPSD, there remain gaps. For example, the dependence modeling used in HRA quantification is largely based on THERP and may prove incompatible with the longer time windows of many LPSD activities.

HRA Needs: Several LPSD HRA needs were identified by the SMEs, including the need for more explicit modeling of errors of commission-those behaviors people can actively perform to create a deficiency at the plant; determining the adequacy of procedures for LPSD activities; identifying similarities and differences between LPSD maintenance activities at current plants and at-power maintenance activities in advanced reactors; establishing credible lower bounds for quantification of LPSD events (i.e., in practice long time windows have been used to justify unrealistically low human error probabilities); and developing more comprehensive dependence models for HRA quantification of LPSD events.

\section{c) Licensing}

Licensing encompasses power uprate amendments and new reactor applications, whereby the objective is to determine the adequacy of the plant design or redesign by assessing the peer review findings of the submitted HRA (See Fig. 1). Licensing review is coordinated by the U.S. NRC, although the submittals are licensee driven and externally peer reviewed.

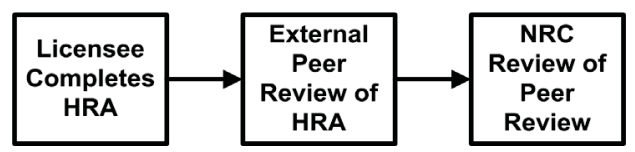

Fig. 1. HRA licensing process

Because the HRA submittals represent a risk assessment on a new design or design modification, they represent a prospective quantitative HRA. Most submittals use some combination of the HRA methods featured in the EPRI HRA Calculator $^{\circledR}$. Power uprate amendments are not required to be risk informed, since primarily the time windows are affected, and these windows are not typically so significantly changed as to represent a safety challenge requiring new plant modeling. As such, power uprate amendments may not feature a detailed quantitative HRA. New reactor applications may address human factors issues that may be more representative of qualitative than quantitative HRA, but a quantitative HRA at some level is usually involved.
HRA Needs: The consensus among the SMEs was that the current comprehensive peer review process ensures the adequacy of the HRA. However, there is no formal guidance on the suitability of different HRA methods for specific applications, particularly with regard to new reactor requirements. Technological advances in control roomsespecially digital instrumentation and control systems as well as increased opportunities for automation - are areas that are not adequately addressed by current HRA methods. There has been no guidance produced to date on adapting existing HRA methods to these applications.

\section{d) Human factors}

Human factors engineers work to ensure the safe interaction of humans with technology, both in terms of improving safety in existing processes and in reviewing novel technologies affecting plant staff. There is clear guidance [10] for the intersection of human factors with HRA and PRA. The discipline of human factors has provided considerable design guidance [11], but it has not typically provided prioritization of guidance. The SMEs suggested that one way to improve the effectiveness of human factors guidance would be to provide metrics like risk prioritization to help ensure the implementation of the most safety-critical facets of new designs. Such prioritization might be seen by infusing HRA quantification ideas into human factors. The type of guidance currently provided by human factors is not unlike qualitative HRA, and a more harmonized approach to presentation of findings might afford greater interactions between the two domains. Moreover, there was a desire expressed by the SMEs that human factors studies might serve as the empirical basis to validate HRA. Such an approach was recently undertaken in the International HRA Empirical Study [12], in which a control room simulator study served as the basis for comparing predictions made by different HRA methods.

HRA Needs: The intersection of human factors and HRA could be strengthened. Human factors could benefit from the use of risk metrics borrowed from HRA to prioritize design guidance. In turn, HRA could benefit from the use of human factors studies to validate HRA predictions.

\section{e) Severe accident mitigation}

Severe accident mitigation and management focuses on determining and mitigating unsafe human actions occurring due to a severe accident or, in some cases, unsafe human actions triggering an accident. Such analyses tend to be prospective and qualitative in nature. As is the case with Level 2 and 3 PRAs (i.e., post core melt and environmental damage, respectively), HRA is a new area of focus for which the specific methods and details have not yet been determined.

HRA Needs: According to the SMEs who were interviewed, the primary HRA needs for severe accident mitigation center on determining how much emphasis HRA should receive and in thoroughly documenting those human activities that could lead to or exacerbate severe accident situations, including the 
recent post-Fukushima introduction of emergency mitigation equipment at plants.

\section{f) Fire}

Fires trigger a unique configuration of human activities at the plant that merit special consideration in HRA modeling. Some activities during a fire may parallel those found during severe accidents, but the fire context includes special operating procedures, potential station blackout and control room abandonment scenarios, activation of onsite fire brigades, and an increased reliance on remote manual controls to prevent spurious equipment activation. HRA SMEs are involved in assessing unsafe human actions during fires, including researchers who are working with industry to develop a guideline for performing fire HRA, which includes the development of a new HRA scoping approach [8] to support quantification of fire-specific human actions.

HRA Needs: The primary HRA need for fire is the refinement and validation of the tailored fire HRA method, including the adaptation of the method under development for use in LPSD fire applications. Similar considerations exist for flooding and seismic events, and the parallels between fire, flooding, and seismic events should be identified. To the degree there is considerable overlap, the insights from applying HRA for one type of event should be generalized to the other types of events. Where there are differences, there is need for standalone guidance and, in some cases, new HRA approaches.

\section{g) Spent fuel handling}

HRA within spent fuel handling aims to determine and mitigate unsafe human actions such as cask drops. SMEs report this area has recently been identified for greater focus. While HRA has not been a requirement for industry or event review in the past, a new qualitative prospective approach to HRA is being developed in coordination with U.S. NRC based on the ATHEANA method [13]. The principle objective of this HRA method is to gain insights to prevent possible cask drops and to improve inspection procedures. This method has implications for industry, and utilities are becoming increasingly aware of the need to model hazards in spent fuel handling.

HRA Needs: It is recognized by SMEs that the domain of spent fuel handling shares similarities to other ex-control room activities such as maintenance tasks during LPSD. It is desirable that HRA development activities with overlapping interests should work together to minimize duplicate efforts.

\section{OVERARCHING HRA NEEDS FOR CURRENT AND FUTURE APPLICATIONS}

A number of overarching challenges were identified with current methods, including:
1. HRA methods were not originally designed for many emerging applications such as human actions in fire, LPSD, spent fuel handling and storage, and new reactors. Current HRA methods may not generalize well to such analyses, or if they do, the human error probabilities (HEPs) generated may not have a clear pedigree.

2. The current guidance for HRA methods is inadequate for some applications. Examples and guidance for HRA applications such as noted in the previous bullet are often nonexistent. The lack of examples and guidance is believed by several SMEs to have the potential to increase inter-analyst variability.

3. Currently, there is limited method-specific HRA training available. Most HRA courses offered to date have been survey courses and have provided limited hands-on training on specific methods. The course offerings should be expanded to include method-specific training in addition to the current survey courses. A notable exception is the training provided by EPRI for the EPRI HRA Calculator ${ }^{\circledR}$, which offers a very practical, hands-on approach.

4. There are few dedicated HRA staff at plants to support analyses. Risk analysts are sometimes tasked with complex human actions to analyze without requisite HRA expertise. The process of finding such competence can significantly lengthen the time required to complete the analysis. Having on-call support within utilities for HRA questions would eliminate much of the uncertainty in performing such analyses.

5. Current HRA methods may not adequately address areas like errors of commission, crew variability, latent errors, recovery actions, and dependency analysis. These topics are the source of considerable uncertainty in HRAs. In the case of errors of commission, this area is the major driver for human error in new reactor control rooms, but there is little guidance on how to address them in this application.

In addition to the application-specific HRA needs outlined in Section II.B.2, the SMEs identified a number of overarching HRA needs during the interviews, including:

6. The need to maintain the simplicity of current simplified approaches like CBDT and SPAR-H but the flexibility to include additional insights from more detailed HRA methods. This may take the form of hybrid approaches or guidance for combining the results across different methods.

7. The need to utilize qualitative insights in addition to quantification in HRAs. The value of qualitative insights is not always highlighted in HRA method documentation, yet it was mentioned in several interviews as being a cornerstone of HRA that is often omitted in the interest of simplicity.

8. The need for HRA beyond Level 1 (i.e., pre core melt) PRA. Numerous human actions related to external events, 
rare events, and severe accidents have not been addressed extensively in PRAs and HRAs to date.

9. The need for improvements in the quantitative basis of HRA methods. HEPs are central to risk-informed decision making, but in many cases these HEPs are not clearly traceable to empirical evidence for specific applications. Moreover, much of quantification is based on legacy firstgeneration HRA methods. Such methods, which predate current plant technologies, may prove inadequate for determining the safety of advanced plant designs.

10. The need to consider alternative approaches to risk analysis, notably safety cases and resilience engineering. These approaches are evidentiary, without being heavily probabilistic or quantitative. SMEs believe such approaches may hold promise for understanding how to prevent human error, not just quantify its occurrence.

\section{CONCLUSIONS}

The purpose of this survey was to identify current and future HRA needs within the U.S. nuclear industry. These needs are far from unique to the nuclear industry and are in many cases shared by other industries that use HRA such as aviation or oil and gas. The ultimate utility of such a survey comes from the improvements it helps to bring about in HRA methods and their use in a diverse range of applications.

A number of HRA needs identified in this paper are already being addressed in research. These advances still leave a number of areas for future work - including the refinement of method-specific guidance to improve consistency and the refinement of the actual methods to address areas such as advanced reactors. It is anticipated that improvements in methods and their guidance will readily generalize to cover additional applications and even new industries that have found limited utility in HRA to date.

Lest this paper be seen as a laundry list of what's wrong with HRA, this paper should not be considered a dire prognosis for the field. Many of the shortcomings addressed in earlier critiques of HRA, e.g., [14], are no longer relevant. The field has matured considerably since its earliest days. This survey paints a portrait of a field that has matured but that still has a vibrant future ahead of it. There is much research, development, and guidance work that can and must still be done in HRA. HRA is already undertaking these new directions, and there is good reason to have full confidence that the field will successfully address any issues raised by this survey. However, as new approaches to HRA are developed or refined, it is wise to consider the HRA needs posed by this paper.

\section{DISCLAIMER}

The author gratefully acknowledges the anonymous SMEs who participated in this survey. This work of authorship was prepared as an account of work sponsored by an agency of the
United States Government. Neither the United States Government, nor any agency thereof, nor any of their employees makes any warranty, express or implied, or assumes any legal liability or responsibility for the accuracy, completeness, or usefulness of any information, apparatus, product, or process disclosed, or represents that its use would not infringe privately-owned rights. Idaho National Laboratory is a multi-program laboratory operated by Battelle Energy Alliance LLC, for the United States Department of Energy under Contract DE-AC07-05ID14517.

\section{REFERENCES}

[1] D. Gertman, H. Blackman, J. Marble, J. Byers, L. Haney, and C. Smith, "The SPAR-H Human Reliability Analysis Method," NUREG/CR-6883, U.S. Nuclear Regulatory Commission, Washington, DC, 2005.

[2] U.S. Nuclear Regulatory Commission, "Technical Basis and Implementation Guidelines for A Technique for Human Event Analysis (ATHEANA)," NUREG-1624, U.S. Nuclear Regulatory Commission, Washington, DC, 2000.

[3] J. Forester, A. Kolaczkowski, S. Cooper, D. Bley, and E. Lois, "ATHEANA User's Guide," NUREG-1880, U.S. Nuclear Regulatory Commission, Washington, DC, 2007.

[4] A.D. Swain and H.E. Guttman, "Handbook of Human Reliability Analysis with Emphasis on Nuclear Power Plant Applications, Final Report," NUREG/CR-1278, U.S. Nuclear Regulatory Commission, Washington, DC, 1983.

[5] A.D. Swain, "Accident Sequence Evaluation Program Human Reliability Analysis Procedure," NUREG/CR-4772, U.S. Nuclear Regulatory Commission, Washington, DC, 1987.

[6] J.A. Julius and J.F. Grobbelaar, "Integrating human reliability analysis approaches in the EPRI HRA Calculator, ${ }^{\mathbb{N}}$ " Proceedings of the 8th International Conference on Probabilistic Safety Assessment and Management, American Society of Mechanical Engineers, New Orleans, 2006.

[7] G.W. Parry, B.O.Y. Lydell, A.J. Spurgin, P. Moleni, and A. Beare, "An Approach to the Analysis of Operator Actions in Probabilistic Risk Assessment," TR-100259, Electric Power Research Institute, Palo Alto, 1992.

[8] U.S. Nuclear Regulatory Commission, "EPRI/NRC-RES Fire Human Reliability Analysis Guidelines," NUREG-1921/EPRI 1019196, U.S. Nuclear Regulatory Commission, Washington, DC, 2012.

[9] U.S. Nuclear Regulatory Commission, "Reactor Oversight Process SelfAssessment Program," NRC Inspection Manual, Manual Chapter 0307, U.S. Nuclear Regulatory Commission, Washington, DC, 2009.

[10] J.M. O'Hara, J.C. Higgins, J.J. Persensky, P.M. Lewis, and J.P. Bongarra, "Human Factors Engineering Program Review Model," NUREG-0711, Rev. 3, U.S. Nuclear Regulatory Commission, Washington, DC, 2013.

[11] J.M. O'Hara, W.S. Lewis, P.M. Lewis, and J.J. Persensky, "HumanSystem Interface Design Review Guidelines," NUREG-0700, U.S. Nuclear Regulatory Commission, Washington, DC, 2004.

[12] E. Lois, V.N. Dang, J. Forester, H. Broberg, S. Massaiu, M. Hildebrandt, P.Ø. Braarud, G. Parry, J. Julius, R. Boring, I. Männistö, and A. Bye, "International HRA Empirical Study_-Phase 1 Report, Description of Overall Approach and Pilot Phase Results from Comparing HRA Methods to Simulator Performance Data," NUREG/IA-0216, Vol. 1, U.S. Nuclear Regulatory Commission, Washington, DC, 2009.

[13] J.D. Brewer, S.M.L. Hendrickson, R.L. Boring, and S.E. Cooper, "Qualitative Human Reliability Analysis-Informed Insights on Cask Drops," Proceedings of the 10th International Conference on Probabilistic Safety Assessment and Management, American Society of Mechanical Engineers, Seattle, 2010.

[14] E.M. Dougherty, Jr., "Human Reliability Analysis-Where Shouldst Thou Turn?," Reliability Engineering and System Safety, vol. 29, pp. 283-299, 1990. 